14,12

\title{
Самоорганизация кластеров фаз в однородно неупорядоченных полимерных композиционных материалах
}

\author{
(С) Д.В. Новиков \\ Санкт-Петербургский государственный лесотехнический университет им. С.М. Кирова, \\ Санкт-Петербург, Россия \\ E-mail: dvnovikov65@mail.ru
}

(Поступила в Редакцию 14 марта 2018 г.)

Представлены данные электронной микроскопии поверхности однородно неупорядоченных полимерных композитных пленок и покрытий, полученных из смесей ограниченно растворимых или взаимонерастворимых компонентов. Обсуждается характерная самоорганизация кластеров фаз в образцах, в результате которой одна фаза образует структурный каркас композита - внутренний перколяционный кластер частиц. Полости кластера, соответствующие дискретным агрегатам частиц другой фазы, характеризуются относительно узким распределением по размеру гауссового типа. Такая топологическая структура композитов возникает при соблюдении необходимого концентрационного режима их получения или же при применении модификаторов, управляющих агрегацией частиц. Самоорганизация кластеров фаз минимизирует производство энтропии при смешении компонентов и создает локальный порядок в пространственном чередовании агрегатов частиц. С ростом величины масштаба локальный порядок переходит в ячеистый беспорядок.

DOI: 10.21883/FTT.2018.09.46406.067

\section{1. Введение}

Формирование упорядоченных структур в полимерных композитах за счет самоорганизации надмолекулярных образований представляет особый интерес как в связи с проблемой теоретического объяснения корреляций типа структура-свойства, так и в связи с задачей создания новых классов твердофазных материалов [1]. При вариации химического строения макромолекул, природы и распределения функциональных групп можно целенаправленно создавать регулярные структуры, например, в блок-сополимерах [2,3], сетчатых полимерах [4,5] и так называемых микрогибридных полимер-неорганических композитах, содержащих нанокластеры металлов [6,7] или атомные кластеры углерода [8].

В работах $[5,9,10]$ методом электронной микроскопии был обнаружен особый тип самоорганизации кластеров фаз на поверхности однородно неупорядоченных полимерных пленок и покрытий, полученных из смесей ограниченно растворимых или взаимонерастворимых компонентов. Смеси представляли собой либо раствор двух ограниченно совместимых олигомеров в общем растворителе [5], либо микрогетерогенную дисперсную систему, содержащую полимерный компонент в растворенном состоянии $[9,10]$. Образцы композитов формировались на твердой подложке при испарении растворителя в различных температурных режимах.

Характерная самоорганизация выражалась в возникновении локального порядка в пространственном чередовании агрегатов частиц, относимых к какойлибо конкретной фазе. При этом частицы одной фазы формировали структурный каркас композита - бес- конечный фрактальный кластер, хаусдорфова размерность $D$ которого в двумерном пространстве была близка к величине 1.9 для так называемого внутреннего перколяционного кластера [11]. Дискретные полости данного кластера заполняли агрегаты частиц другой фазы.

В образцах были обнаружены два характерных масштаба $[5,9,10]$. На масштабе $R<\xi_{1}$ радиальная функция $g(R)$ распределения плотности бесконечного кластера изменялась немонотонно, достигая локального максимума при $R=\xi_{1}$. На масштабе $\xi_{1}<R<\xi_{2}$, где $\xi_{1}$ и $\xi_{2}$ - корреляционные длины, система являлась однородно неупорядоченной, и функция $g(R)$ монотонно убывала, приближаясь к единице. Переход типа порядок-беспорядок и фрактальная структура бесконечного кластера частиц были характерны для изученных композиционных систем на масштабе $\xi_{1}<R<\xi_{2}[5,9,10]$, несмотря на различную химическую природу компонентов.

Важно отметить, что локальный порядок в чередовании агрегатов частиц возникал при соблюдении необходимого концентрационного режима получения образцов или же при применении модификаторов, адсорбируемых поверхностью частиц и тем самым влияющих на их агрегацию.

Настоящая работа продолжает проведенные ранее исследования $[5,9,10]$ в плане детального изучения кластерной структуры композитов на масштабе $R<\xi_{1}$ и установления особенностей топологического беспорядка на масштабе $\xi_{1}<R<\xi_{2}$. Цель работы - выявление признаков и следствий характерной самоорганизации кластеров фаз в однородно неупорядоченных полимерных композиционных материалах. 


\section{2. Методики электронно-микроскопического исследования}

Для изучения топологической структуры поверхности образцов использовались сканирующая электронная микроскопия (SEM) [10] и просвечивающая электронная микроскопия (ТЕM) в варианте декорирования поверхности наночастицами хлорида серебра с последующим снятием опорной угольной реплики [5,9].

Компьютерный анализ изображений SEM проводился с применением квадратной решетки с расстоянием между узлами $r \ll \xi_{1}$. Помечались узлы решетки, маркирующие детали изображения, и рассчитывались средняя решеточная плотность кластеров фаз, значения площади дискретных кластеров, а также радиальные функции $g(R)$ распределения решеточной плотности по методике [10] с шагом сканирования изображения $\delta \approx r$.

Ближний порядок в квазирешетке декорирующих наночастиц на изображениях ТЕМ определялся с помощью радиальной функции $g(R)$ распределения, полученной при $\delta \ll r$, где $r-$ наиболее вероятное расстояние между частицами. Корреляции плотность-плотность и корреляционные длины определялись с помощью „крупнозернистой“ фуннкции $g(R)$ при $\delta \geq r[5]$. При близости значений $r$ и $\xi_{1}$ использовалась наложенная на изображение квадратная решетка. Маркируемые узлы решетки в окрестности декорирующих наночастиц выбирались по методике [12]. По этой же методике осуществлялось и выделение из общего ансамбля наночастиц подансамбля, соответствующего структурному каркасу композита внутреннему перколяционному кластеру.

\section{3. Объекты исследования}

Образец № 1 представлял собой полимерное покрытие толщиной $\sim 5 \mu \mathrm{m}$, сформированное на стекле при $298 \mathrm{~K}$ из мицеллярного раствора желатина (средневязкостная молекулярная масса $\left.M_{v}=10.3 \cdot 10^{4}\right)$ в системе изооктан-вода-(бис-2-этилгексил)сульфосукцинат натрия (АОТ) по методике [9]. Мольное отношение $\left[\mathrm{H}_{2} \mathrm{O}\right] /[\mathrm{AOT}]=40$. Концентрация раствора $c$ соответствовала критическому значению $c^{*}[13]$, при котором происходит гелеобразование, т.е. образуется непрерывная флуктуационная сетка зацеплений макромолекул. Структура поверхности покрытия визуализировалась методом ТЕМ с применением вакуумного термического декорирования наночастицами хлорида серебра, имеющим сродство к аминным и карбоксильным функциональным группам желатина [9].

В покрытии, получаемом из мицеллярного раствора желатина при $c=c^{*}$, наблюдается суперпозиция физической сетки зацеплений макромолекул (внутреннего перколяционного кластера) и наноглобул полимера, находящихся в ячейках сетки (рис. $1, a$ ). При этом сетка макромолекул отображается мелкими декорирующими

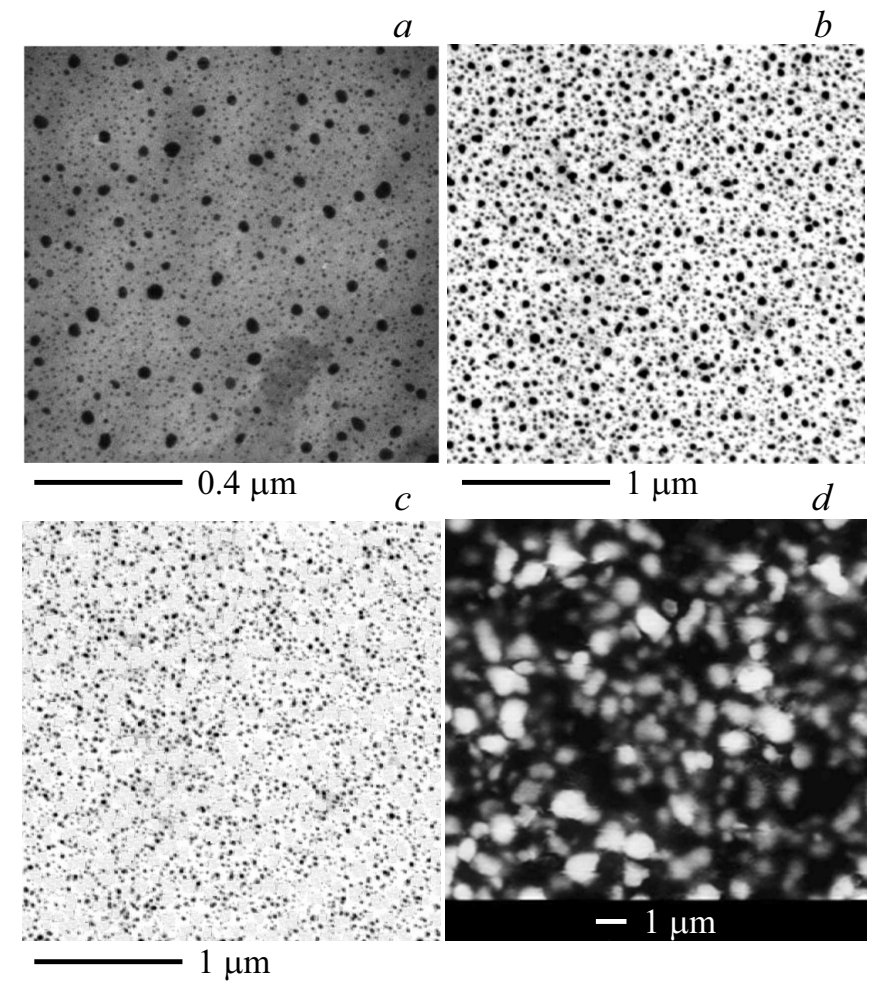

Рис. 1. Электронно-микроскопические изображения поверхности: образца № 1, декорированного наночастицами $\mathrm{AgCl}(a)$; образца № 2, декорированного наночастицами $\mathrm{AgCl}(b)$; внутренний перколяционный кластер наночастиц $\mathrm{AgCl}$ в образце № 2 (c); образца № $3(d)$.

частицами, а глобулярному состоянию полимера отвечают крупные частицы $\mathrm{AgCl}$.

В качестве образца № 2 выступало покрытие (толщина $\sim 15 \mu \mathrm{m})$ сшитого эпоксифенольного полимера (ЕР) на жести. Образец был сформирован из раствора так называемого форконденсата на основе смеси $([\mathrm{EO}] /[\mathrm{PO}]=1: 1)$ эпоксидного (ЕО) олигомера (среднечисленная молекулярная масса $M_{n}=3400$ ) и фенолформальдегидного (PО) олигомера $\left(M_{n}=860\right)$ [5]. Композиция подвергалась термическому отверждению при $483 \mathrm{~K}$. Концентрация раствора превышала в 1.5 раза значение $c^{*}$, соответствующее образованию бесконечного кластера олигомерных молекул. В этом случае в растворе имело место микрофазовое разделение компонентов по механизму нуклеации и роста фрактальных кластеров ЕО, что приводило к образованию в покрытии внутреннего перколяционного кластера, отображающего химическую сетку сшитого ЕО. Полости этого кластера заполнялись фазой сшитого ЕР полимера [5].

Поверхность образца № 2 была декорирована наночастицами $\mathrm{AgCl}$, образование и рост которых происходили под влиянием функциональных групп сшитого полимеpa [5]. Изображение ТЕМ угольной реплики с наночастицами $\mathrm{AgCl}$ представлено на рис. $1, b$, а на рис. $1, c$ приведен внутренний перколяционный кластер фазы 
сшитого ЕО, отображаемый подансамблем наночастиц $\mathrm{AgCl}$. Выделенный подансамбль наночастиц получен при обработке полного ансамбля (рис. $1, b)$ по методике [5].

Образцом № 3 являлся полимерно-неорганический композит на основе цианэтилового эфира поливинилового спирта (CEPVA, $\left.M_{n}=5 \cdot 10^{4}\right)$ и микрочастиц титаната бария $\left(\mathrm{BaTiO}_{3}\right)[10]$. Композитная пленка (40 vol.\% фазы $\mathrm{BaTiO}_{3}$ ) толщиной $\sim 100 \mu \mathrm{m}$ была получена при диспергировании микрочастиц $\mathrm{BaTiO}_{3}$ среднего размера $\sim 0.6 \mu \mathrm{m}$ в пленкообразующем растворе полимера с последующим нанесением композиции на подложку и вакуумной сушкой при 298 K [10]. Микрочастицы были модифицированы нанокластерами шунгитового углерода (0.04 mass.\% в расчете на фазу $\left.\mathrm{BaTiO}_{3}\right)$. Ранее было установлено [10], что ближний порядок микрочастиц $\mathrm{BaTiO}_{3}$ зависит от интенсивности их агрегации, проходящей под влиянием шунгитового углерода. Графеновые нанокластеры шунгитового углерода способны выступать в роли структурного модификатора за счет своего взаимодействия с поверхностью микрочастиц неорганической фазы [14]. При таком взаимодействии уменьшается вероятность слипания и взаимопроникновения частиц $\mathrm{BaTiO}_{3}$. При указанном соотношении шунгитовый углерод/ $/ \mathrm{BaTiO}_{3}$ в композитной пленке формируется внутренний перколяционный кластер агрегированных микрочастиц $\mathrm{BaTiO}_{3}$. На рис. $1, d$ приведено изображение SEM этого кластера.

\section{4. Результаты и их обсуждение}

На рис. 2 представлены радиальные функции $g(R)$ распределения плотности внутренних перколяционных кластеров, отображающих одну из фаз на поверхности образцов. Эти кластеры выступают в роли структурного каркаса композитов. На масштабе $\xi_{1}<R<\xi_{2}$, где $\xi_{1}$ - наиболее вероятное расстояние между агрегатами частиц, кластеры фрактальны, и функции $g(R)$ следуют степенному закону $g(R) \propto R^{-0.1}$, отвечающему величине хаусдорфовой размерности $D \sim 1.9$. Максимум функций $g(R)$ при $R=\xi_{1}$ указывает на локальный порядок в чередовании агрегатов частиц в образцах. Функции $g(R)$ подобны друг другу, отличаясь только величиной масштаба. Важно отметить, что во всех случаях соблюдается соотношение $\xi_{2} / \xi_{1}=2-3$, а доля двумерного пространства, занятая кластерами, изменяется от 0.45 для образца № 1 до $0.65 \pm 0.02$ для образца № $3[5,9,10]$.

Дискретные полости во внутренних перколяционных кластерах соответствуют агрегатам частиц другой фазы и характеризуются относительно узким распределением по размеру гауссового типа. Об этом свидетельствуют функции $f(S)$ распределения полостей по площади (рис. 3). Подобный результат был получен ранее для наноглобул желатина в образце № 1 [9]. Такая особенность полостей в структурном каркасе образцов композитов отличает этот каркас от внутреннего перколяционного кластера, возникающего при случайном
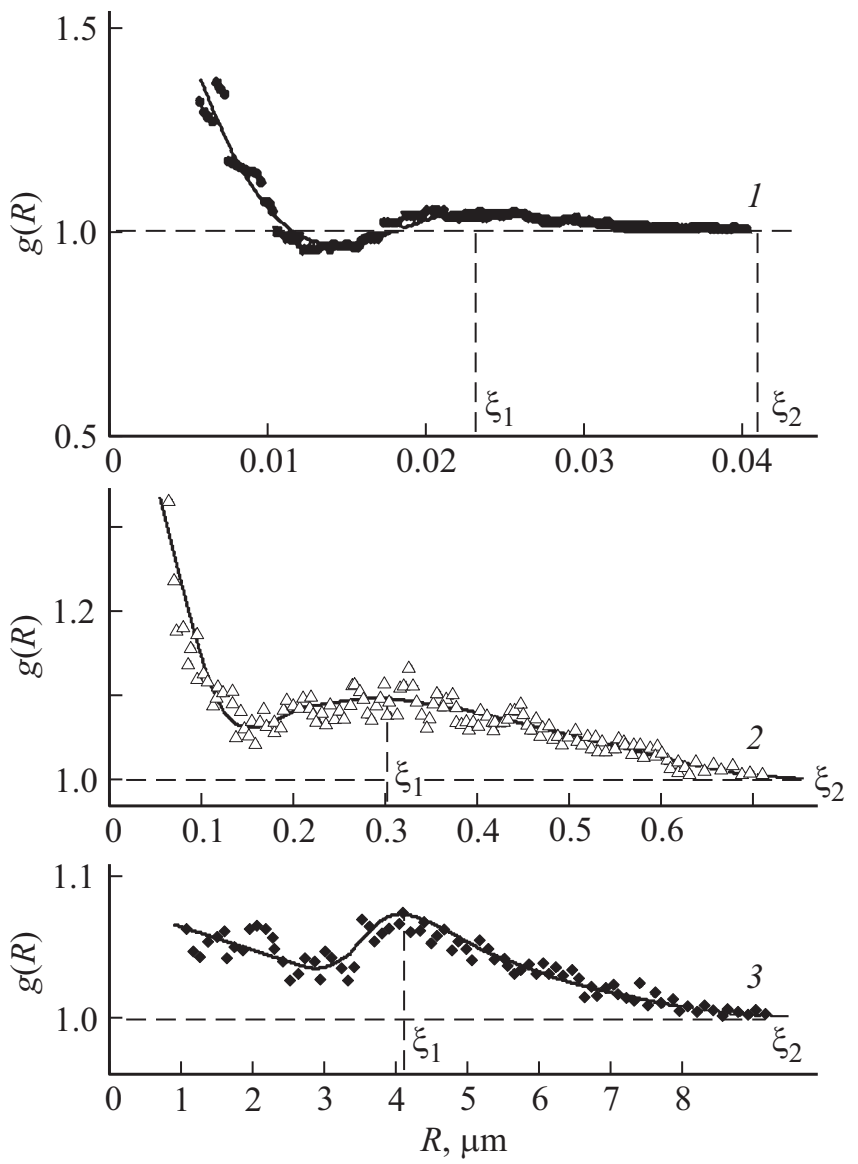

Рис. 2. Радиальные функции $g(R)$ распределения решеточной плотности внутреннего перколяционного кластера на поверхности: образца № 1 (кривая 1); образца № 2 (кривая 2); образца № 3 (кривая 3).

заполнении узлов решетки частицами и содержащего полости всех возможных размеров [11]. Таким образом, если в классической решеточной модели внутреннего перколяционного кластера реализуется континуальный беспорядок, то в изученных образцах проявляется так называемый ячеистый беспорядок [15].

Тип топологического беспорядка должен предопределять особенности пространственных корреляций „плотность-плотность“, описываемых полной корреляционной функцией $h(R)$, связанной с $g(R)$ уравнением: $h(R)=g(R)-1 \quad[15]$. В однородно неупорядоченных системах функция $h(R)$ описывается выражением типа Орнштейна-Цернике: $h(R) \propto R^{-n} \exp (-R / \xi)$ [15], справедливым для флуктуаций плотности в жидкостях и аморфных телах. В материалах с „промежуточным“ или локальным порядком это выражение должно выполняться на масштабе, превышающем размер так называемого „зерна“ материала, т.е. наиболее вероятное расстояние $\xi_{1}$ между локально упорядоченными агрегатами частиц. В работах $[9,15,16]$ было показано, что к типу беспорядка чувствительна величина индекса $n$ в предэкспоненте функции $h(R)$. В частности, переход от 
континуального к ячеистому беспорядку в двумерном отображении поверхности материала трансформирует функцию $h(R)$ за счет изменения индекса $n$ от $n=1$ до $n=2[16]$.

В образцах № 1-3 функции $h(R)$ внутренних перколяционных кластеров на масштабе $\xi_{1}<R<\xi_{2}$ следуют выражению типа Орнштейна-Цернике, и их графики линеаризуются в координатах рис. 4, причем наклон прямых соответствует индексу $n=2$. Функция $h(R) \propto R^{-2} \exp \left(-R / \xi_{2}\right)$ описывает пространственные корреляции в системах с ближним (локальным) порядком и по своему виду аналогична спиновой корреляционной функции в ансамбле спинов на двумерной решетке Изинга ниже критической точки перехода беспорядок-порядок [15]. Отметим, что приведенная выше функция $h(R)$ описывает пространственные корреляции типа „плотность-плотность“ в изинговских полимерных сетках с ближним порядком узлов $[15,16]$.
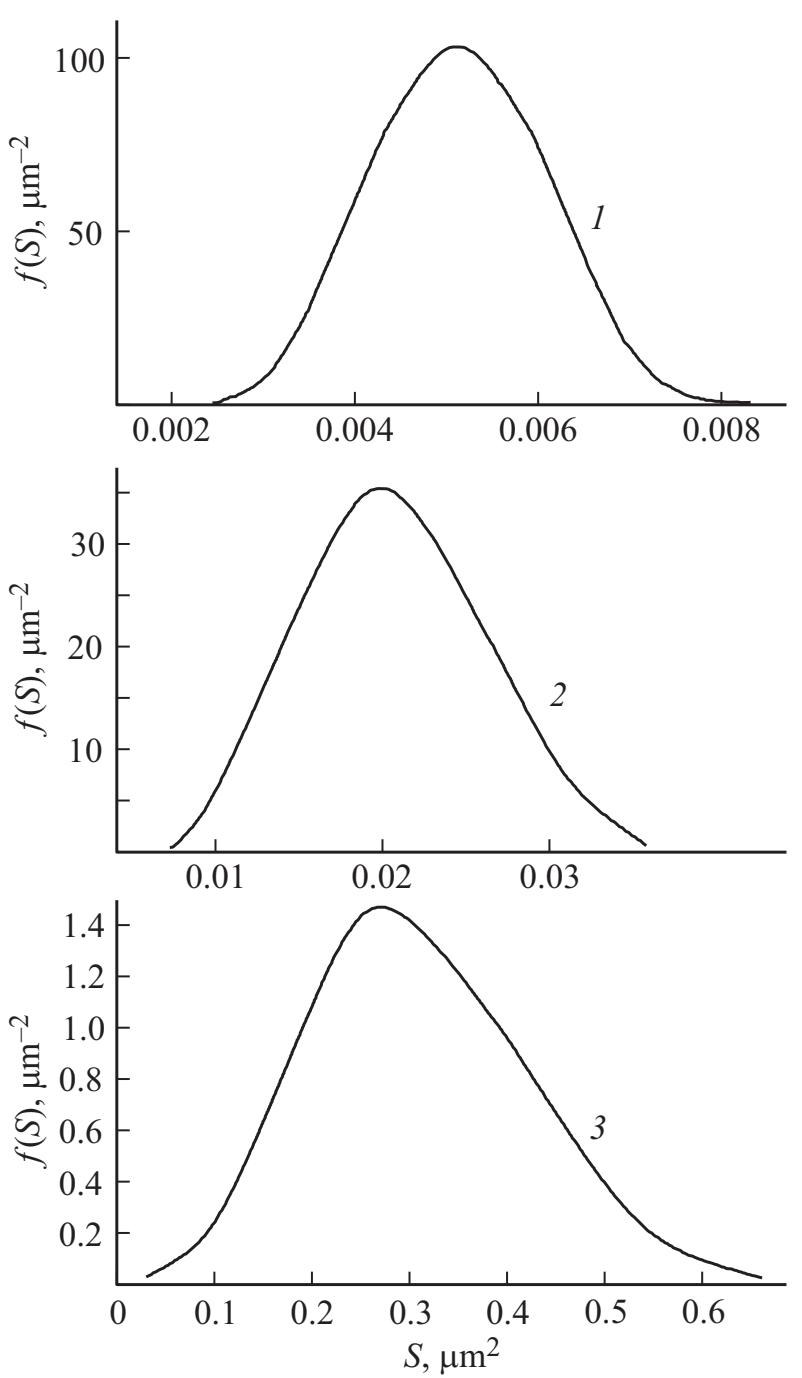

Рис. 3. Нормированные функции $f(S)$ распределения по площади дискретных полостей внутреннего перколяционного кластера в двумерном отображении поверхности образца № 1 (кривая 1); образца № 2 (кривая 2); образца № 3 (кривая 3).
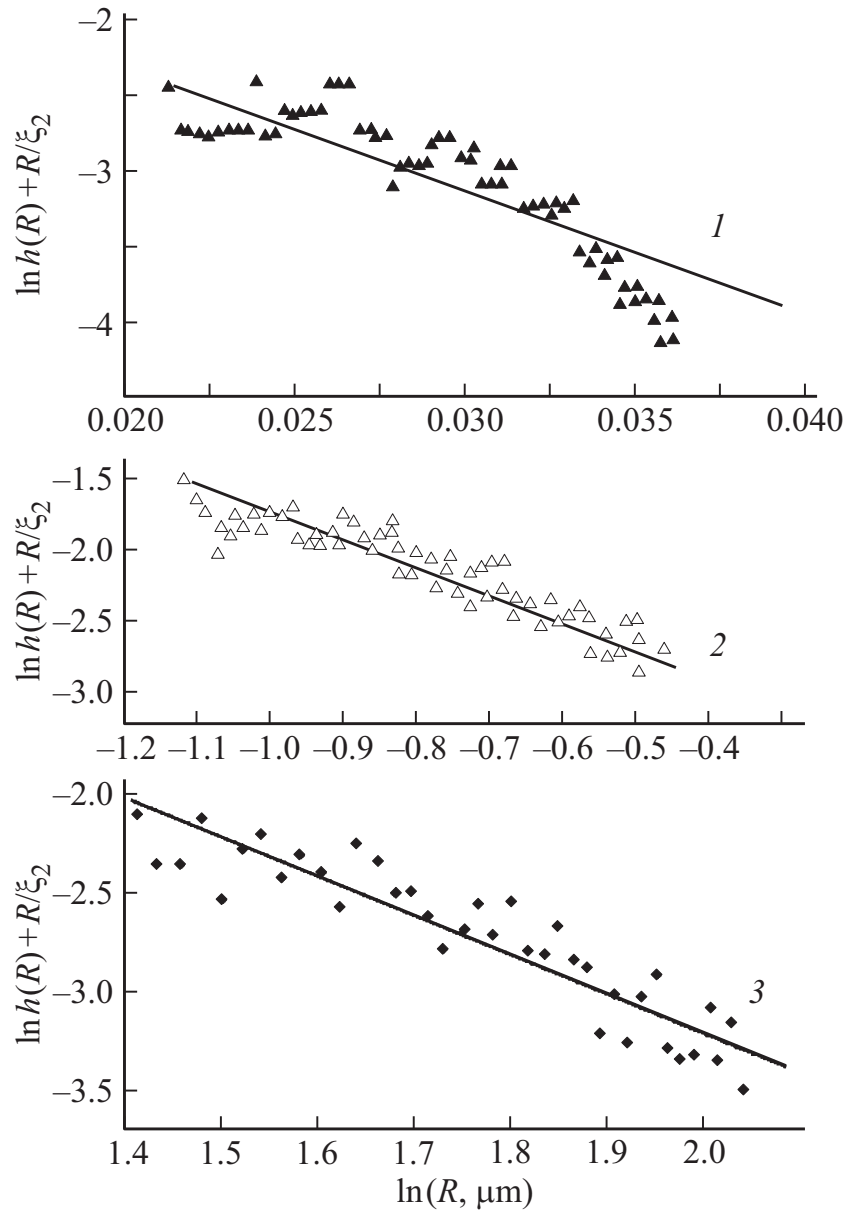

Рис. 4. Линеаризация полных корреляционных функций $h(R)$ „плотность-плотность“, представляемых выражением типа Орнштейна-Цернике, для образца № 1 (кривая 1); образца № 2 (кривая 2); образца № 3 (кривая 3).

Таким образом, в изученных образцах композитов, как и в изинговских полимерных сетках, реализуется ячеистый беспорядок на масштабе, превышающем расстояние между локально упорядоченными структонами. Ячеистый беспорядок в отличие от континуального беспорядка, типичного для однородно неупорядоченных материалов, свидетельствует о структурной самоорганизации системы.

Следует полагать, что при получении образцов композитов самоорганизация кластеров фаз имеет место уже в исходной смеси и приводит к минимизации производства энтропии при смешении компонентов. Управляющим параметром самоорганизации является концентрация $c$ в смеси того компонента, который образует структурный каркас композита. Этим компонентом может быть модифицирующая добавка, влияющая на построение каркаса.

Концентрационный режим получения композитов, отвечающий самоорганизации кластеров фаз, весьма критичен, поскольку небольшие отклонения управляющего параметра от порогового значения изменяют структуру и свойства композитов $[5,9,10]$. 
Специфическая кластерная структура ячеистого типа должна обеспечивать максимальную поверхностную энергию образцов.

В работе [9] методом краевых углов смачивания был установлен максимум поверхностной энергии образца № 3 в ряду композитов CEPVA- $\mathrm{BaTiO}_{3}$ с различным содержанием шунгитового углерода, в том числе и без модификатора.

В образце № 1 наноглобулы полимера имеют максимальный средний размер [9] по сравнению с другими полимерными покрытиями, полученными при вариации концентрации $c$ мицеллярного раствора желатина, поэтому образцу № 1 должен отвечать максимум поверхностной энергии. Отметим, что в покрытиях, полученных при $c>c^{*}$, наноглобулы вообще отсутствуют вследствие их распада в растворе с образованием более плотной сетки геля [9].

Образец № 2 получен из раствора олигомеров ЕО и РО концентрацией $c \sim 1.5 c^{*}$. Согласно данным работы [17], такой раствор по шкале параметра $c$ характеризуется максимальным значением поверхностного натяжения на границе раздела с воздухом. Аналогичный результат был получен в работе [18] на примере дисперсной системы, служащей основой для получения металлонаполненных композитных пленок натрийкарбоксиметилцеллюлозы. Такие пленки имеют ячеистую структуру, каркас которой формирует полимерный компонент [18].

\section{5. Заключение}

В однородно неупорядоченных полимерных композиционных материалах, полученных из смесей ограниченно растворимых или взаимонерастворимых компонентов, может возникать характерная самоорганизация кластеров фаз. В результате чего независимо от химической природы компонентов одна из фаз формирует структурный каркас композита - внутренний перколяционный кластер частиц, хаусдорфова размерность которого в двумерном пространстве составляет $\sim 1.9$. Полости этого кластера, заполняемые дискретными агрегатами частиц другой фазы, имеют относительно узкое распределение по размеру гауссового типа. Двухуровневая структура композитов характеризуется двумя значениями корреляционной длины $-\xi_{1}$ и $\xi_{2}$, причем $\xi_{2} / \xi_{1}=2-3$. На масштабе $R<\xi_{1}$ сушествует локальный порядок в чередовании агрегатов частиц, а при $\xi_{1}<R<\xi_{2}$ материал является однородно неупорядоченным. Полная корреляционная функция $h(R)$ типа „плотность-плотность“ на масштабе $\xi_{1}<R<\xi_{2}$ допускает аппроксимацию выражением $h(R) \propto R^{-2} \exp \left(-R / \xi_{2}\right)$, свидетельствующим об ячеистом беспорядке в структуре композитов.

Самоорганизация кластеров фаз возникает при соблюдении необходимого концентрационного режима получения композитов или при использовании структурных модификаторов, регулирующих процесс агрегации частиц. Управляющим параметром самоорганизации является концентрация того компонента в смеси, который образует структурный каркас композита или влияет на его построение.

\section{Список литературы}

[1] М.Л. Кербер. Полимерные композиционные материалы: структура, свойства, технология / Под ред. А.А. Берлина. Профессия, СПб. (2008). 560 с.

[2] A.-V. Ruzette, L. Leibler. Nature Mater. 4, 19 (2005).

[3] И.В. Нератова, А.С. Павлов, П.Г. Халатур. Высокомолекуляр. соединения А 52, 1 (2010).

[4] Heterophase Network Polymers: Synthesis, Characterization, Properties / Eds B.A. Rosenberg, G.M. Sigalov. Taylor \& Francis Books. London (2001). 336 p.

[5] Д.В. Новиков, А.Н. Красовский, В.Н. Филиппов. ФТТ 56. 2246 (2014).

[6] И.П. Суздалев. Физикохимия нанокластеров, наноструктур и наноматериалов. КомКнига, М. (2006). 592 с.

[7] S. Li, M. Meng Lin, M.S. Toprak, D.K. Kim, M. Muhammed. Nano Rev. 1, 1 (2010).

[8] K. Chrissafis, K.M. Paraskevopoulis, I. Tsiaoussis, D. Bikiaris. J. Appl. Polymer Sci. 114, 1606 (2009).

[9] Д.В. Новиков, А.Н. Красовский. ФТТ 54. 2180 (2012).

[10] А.Н. Красовский, Д.В. Новиков, Е.С. Васина, П.В. Матвейчикова, М.М. Сычев, Н.Н. Рожкова. ФТТ 57. 2479 (2015).

[11] Е. Федер. Фракталы. Мир, М. (1991). 254 с. [J. Feder. Fractals. Plenum Press, N. Y., London (1988). 260 p.].

[12] Д.В. Новиков, А.Н. Красовский. ФТТ 54. 382 (2012).

[13] Г.М. Бартенев, С.Я. Френкель. Физика полимеров. Химия, Л. (1990). 432 c.

[14] В.В. Ковалевский. Структура углеродного вещества и генезис шунгитовых пород. Докт. дис. Петрозаводск (2007). $350 \mathrm{c}$.

[15] Дж. Займан. Модели беспорядка. Мир, М. (1982). 529 с. [J.M. Ziman. Models of Disorder. Cambridge Univ. Press, London (1979). 480 p.].

[16] Д.В. Новиков, А.Н. Красовский. ФТТ 54. 1582 (2012).

[17] А.Н. Красовский, В.Н. Филиппов, Д.В. Новиков. ЖПХ 80 , 1190 (2007).

[18] Н.М. Антонова. Разработка композиционных материалов на основе полимера Na-КМЦ с металлическими порошковыми наполнителями для формирования функциональных покрытий и пористых пленок. Докт. дис. Новочеркасск (2015). 325 c.

Редактор Ю.Э. Китаев 